\title{
SOCIO-PRAGMATIC MEASUREMENT OF TRANSLATOLOGY PARADIGM: COMMUNICATIVE ACTION IN TRANSLATION ${ }^{1}$
}

\author{
Vera A. Mityagina \\ Volgograd State University, Volgograd, Russian Federation
}

\begin{abstract}
The article reveals the explantatory and heuristic possibilities of the socio-pragmatic approach to the analysis of translation based on the use of the typology of communicative actions conditioned by discourse conventions. The relevance of the research is explained by the fact that provisions of the discourse theory and the communication theory are not widely used to study the procedural activity of a translator. The material of the research is represented by globalized (translated into English) and localized (translated into Russian and German) texts of dynamically developing tourism Internet discourse.

The author interprets the communicative action as a procedural unit of research that makes it possible to understand the logic of the translated actions that create the text of translation, and proves the provision (assumption?), that the preservation / change of the type of communicative action explains translational transfromations, since the socio-cultural semiosis in the intercultural space is created by texts as complex communicative signs. Overcoming the resistance of the translation language system is considered by the author to be a formal component of the transformations underway, and it is suggested to distinguish the characteristics of communicative activities determined by discourse as their content component. This approach provides new arguments in favor of understanding translation as a cultural transfer. A translation solution, based on the consideration of the communicative potential of a particular fragment of the text, allows the creation of a secondary text as a communicative sign responsible for the implementation of a comprehensive socio-pragmatic program.

Key words: socio-pragmatic approach, discourse, translation, communicative action, translational action, tourism Internet discourse.

Citation. Mityagina V.A. Socio-Pragmatic Measurement of Translatology Paradigm: Communicative Action in Translation. Vestnik Volgogradskogo gosudarstvennogo universiteta. Seriya 2, Yazykoznanie [Science Journal of Volgograd State University. Linguistics], 2017, vol. 16, no. 3, pp. 30-40. (in Russian). DOI: https://doi.org/ 10.15688/jvolsu2.2017.3.3
\end{abstract}

УДК 81 '25:004.738.5

Дата поступления статьи: 18.04.2017

ББК 81.18

Дата принятия статьи: 30.05.2017

\section{СОЦИОПРАГМАТИЧЕСКОЕ ИЗМЕРЕНИЕ ТРАНСЛАТОЛОГИЧЕСКОЙ ПАРАДИГМЫ: КОММУНИКАТИВНОЕ ДЕЙСТВИЕ В ПЕРЕВОДЕ ${ }^{1}$}

\author{
Вера Александровна Митягина \\ Волгоградский государственный университет, г. Волгоград, Российская Федерация
}


Автор трактует коммуникативное действие как процессуальную единицу исследования, позволяющую понять логику совершаемых переводческих действий, создающих текст перевода, и доказывает положение (предположение?) о том, что сохранение / изменение типа коммуникативного действия объясняет совершаемые переводческие преобразования, поскольку социокультурный семиозис в межкультурном пространстве создается текстами как комплексными коммуникативными знаками. Преодоление сопротивления системы языка перевода рассматривается автором как формальная составляющая совершаемых преобразований, в качестве их содержательной составляющей предложено выделять характеристики коммуникативных действий, детерминированные дискурсом. Такой подход предоставляет новые аргументы в пользу понимания перевода как культурного трансфера. Переводческое решение, основывающееся на учете коммуникативного потенциала отдельного фрагмента текста, позволяет создать вторичный текст как коммуникативный знак, отвечающий за выполнение комплексной социопрагматической программы.

Ключевые слова: социопрагматический подход, дискурс, перевод, коммуникативное действие, переводческое действие, туристический интернет-дискурс.

Цитирование. Митягина В. А. Социопрагматическое измерение транслатологической парадигмы: коммуникативное действие в переводе // Вестник Волгоградского государственного университета. Серия 2, Языкознание. - 2017. - Т. 16, № 3. - C. 30-40. - DOI: https://doi.org/10.15688/jvolsu2.2017.3.3

\section{1}

Наука о переводе на протяжении всей истории своего развития аккумулировала знание гуманитарных дисциплин, связанных с исследованием процесса «переодевания», «перехода», «перевода» мыслей из «пространства» одного языка в «границы» другого языка. Верность перевода как одна из базовых категорий формировалась с теологических позиций, дискутировалась в творческом литературном аспекте, стала предметом многочисленных сопоставительных исследований и выступила основой оппозиции «эквивалентность : : адекватность» в рамках лингвистического подхода к осмыслению процесса и результата перевода [Комиссаров, 1990; Catford, 1965]. Языковеды-переводоведы со всей скрупулезностью и педантичностью подошли к описанию закономерных и вариантных соответствий [Рецкер, 1950; Федоров, 1983], раскрыли логику трансформации языковых структур [Бархударов, 1975; Найда, 1978] и предложили технологию преодоления сопротивления языковых систем [Латышев, 1981; Миньяр-Белоручев, 1980]. Смена исследовательской парадигмы в лингвистике на антропоцентрическую, коммуникативно-прагматическую стала проявлением универсальности социокультурной триады «личность - культура - общество» в изучении эманаций человеческой личности, и наука о переводе, как никакая другая, активно отреагировала на аналитические возможности нового подхода. Многие позиции функци- ональной теории перевода [Reiß, 1995; Reiß, Vermeer, 1984; Vermeer, 1989] как высшей точки коммуникативно-прагматической концепции переводоведения были подготовлены успешно реализованными в науке о переводе установками теории коммуникации [Lasswell, 1948; Shannon, 1948].

Наряду с этим следует отметить безусловное влияние на развитие науки о переводе таких важных антропологических направлений, как теория социального действия, теория коммуникативного действия, теория дискурса и лингвистическая прагматика в целом. Процесс интенсивной интеграции, которая и глобализует, унифицируя, и усиливает центробежные тенденции, детерминирует переводческую практику и наглядно демонстрирует многообразие форм культурной конвенциональности в коммуникации и вариативность компромиссов в формах ее декодирования и передачи. Согласимся с важным для актуальной функциональной теории перевода пониманием активной позиции переводчика в коммуникативном процессе: немецкие исследователи Х. Хениг и П. Кусмауль в своем ставшем программным труде «Стратегия перевода» заявили о том, что переводчик становится активным участником коммуникативного процесса, который «действует и преобразует» (handelt und verwandelt) [Hönig, Kussmaul, 1984, S. 40], а австрийский переводовед Э. Прунч выразил солидарное мнение и отметил, что переводчик не может быть «пассивным трансформатором текста» (passiver Transformator eines Textes) [Prunč, 2002, S. 157]. 
Эти действия и преобразования связаны, по мнению Х. Хенига и П. Кусмауля, со следующими факторами:

1) ситуация, целевая аудитория перевода, ее культура и пресуппозиция;

2) тип текста (Textsorte) как реализация социокультурно обусловленных, конвенционально регулируемых комплексов ситуативных параметров;

3) учет факторов 1-2, зависящий от переводческого задания [Hönig, Kussmaul, 1984, S. 40].

Решения переводчика как «оформителя» транскультурной коммуникации могут быть ориентированы не только на целевую аудиторию и ее горизонт ожидания, но и на коммуникативное задание, обусловленное интересами отправителя. Зависимость методики и технологии перевода от выполняемой текстом коммуникативной функции [Reiß, 1983] предполагает, на наш взгляд, обязательность анализа коммуникативных действий, предпринимаемых в разных дискурсивных жанрах, поскольку ориентированная на цель функциональная теория, или скопос-теория, представлена ее авторами как комбинация двух релевантных для современной переводческой деятельности концепций: теории переводческих действий [Vermeer, 1989] и коммуникативно-прагматической транслатологической типологии текстов [Reiß, 1983].

Переключение исследовательского фокуса на изучение процесса перевода было для науки о переводе поистине поворотным. Результат перевода - вторичный текст (транслят) стал рассматриваться как результат комплекса действий переводчика в заданном социокультурном контексте, «оформление» транслята вышло из «тисков» лингвистической эквивалентности и получило подчиненную целеполаганию роль. В частности, 3.Д. Львовская полагает, что «на основе такого анализа можно было бы сформировать коммуникативные требования, которым должен отвечать конечный продукт деятельности переводчика» [Львовская, 2014, c. 169]. Таким образом, тексты как инструменты коммуникации являют собой комплексы коммуникативных действий, которые в процессе перевода могут быть трансформированы в комплексы других действий, более адекватных в реализации заданной интеракции в пространстве целевой культуры.
Понятия «коммуникативное действие» и «переводческое действие» играют ключевую роль в функционально-теоретическом осмыслении перевода. Ю. Хольц-Мантарри (J. HolzMänttäri) справедливо подчеркивает, что переводчик занимается экспертной деятельностью, которая носит оптимизирующий характер (подробно о концепции Ю. Хольц-Мантарри см.: [Risku, 2006, S. 107-112]).

Процессуальный аспект деятельности переводчика стал, таким образом, актуальным объектом науки о переводе, но для его изучения недостаточно широко используются теоретические положения теории дискурса и теории коммуникации в целом, несмотря на их высокую эвристичность в решении многих проблем гуманитарных исследований, ориентированных на поиск путей оптимизации социальных интеракций.

\section{2}

Представляется необходимым восполнить лакуну в социопрагматической парадигме переводоведения и охарактеризовать коммуникативные действия как инициальные процессуальные единицы дискурса, «несущие конструкции» ситуации межкультурного взаимодействия, выражающие социокультурно обусловленный и лингвокультурно актуализированный смысл. Использование коммуникативного действия в качестве единицы анализа процесса перевода позволяет обеспечить адекватную трансляцию прагматики исходного текста адекватно цели данной межкультурной интеракции.

Становление понятия «коммуникативное действие», безусловно, связано с понятием «социального действия» в рамках «понимающей социологии» М. Вебера, который подчеркивал его интенциональную составляющую: «Но "социальным действием" следует называть такое, которое по своему смыслу, подразумеваемому действующим или действующими, отнесено к поведению других и этим ориентировано в своем протекании» («Soziales» Handeln aber soll ein solches Handeln heißen, welches seinem von dem oder den Handelnden gemeinten Sinn nach auf das Verhalten anderer bezogen wird und daran in seinem Ablauf orientiert ist) [Weber, 1976, S. 15]. 
Схема коммуникативного действия обусловлена универсальными сценариями интеракций, заданными указанными установками. Классифицировать коммуникативные действия в аспекте данной характеристики логично в пределах четырех типов:

- целерациональное коммуникативное действие основывается на четком осознании цели, отличается направленной соотнесенностью с языковыми средствами, адекватными достижению данной объективной цели;

- ценностно-ориентированное коммуникативное действие основывается на вере в безусловную ценность данного действия, самодостаточного и независимого от его возможных результатов. Его смысл, в отличие от целерационального действия, заключается не в достижении внешней цели, а в подчиненности определенным «заповедям» и «требованиям», в следовании которым действующий индивид видит свой долг. Обозначение данного действия как ценностно-ориентированного, а не ценностно-рационального, как у М. Вебера, подчеркивает то обстоятельство, что следование ценностной установке в большом количестве случаев выходит за рамки рационального, реализует социокультурно обусловленную модель коммуникативного поведения [Митягина, 2007, с. 92-101];

- традиционное коммуникативное действие является обусловленным менталитетом, традициями и обычаями процессуальным шагом, свойственным обычному повседневному поведению людей и совершаемым зачастую в «автоматическом режиме»;

- аффективное коммуникативное действие обусловлено эмоциональным состоянием действующего субъекта и совершается как демонстрация данного состояния.

Интенция реализуется как обдуманно, так и спонтанно, поэтому оппозиция «рациональность : : спонтанность» составляет реактивную основу действия. Интерпретация данной оппозиции необходима для понимания взаимодействия «автоматического» и регулятивного механизмов коммуникативного действия в дискурсе.

Координационной характеристикой коммуникативного действия выступает его ориентированность на согласование, иллокуцию или перлокуцию, потому что при его совершении актор может:

- учитывать интерес партнера и согласовывать с ним данное действие;

- стремиться к достижению исключительно перлокутивного эффекта, вне учета позиции партнера;

- добиваться понимания посредством иллокутивной силы используемых языковых средств.

С позиций социокультурной прагматики ориентированность не может быть основанием для оппозиции коммуникативного, социального и стратегического действий, предложенной Ю. Хабермасом [Habermas, 1997, S. 271272], поскольку она является обязательным сопровождением интенциональной характеристики коммуникативного действия.

Безусловную значимость для использования понятия «коммуникативное действие» в анализе переводческих преобразований имеет личная : : статусная маркированность как показатель диапазона интеракционных возможностей индивида в рамках совершаемого действия.

Следует отметить, что анализ коммуникативного действия с позиций социокультурной прагматики будет неполным вне учета единиц социокультурной семиотики, одной из конституирующих категорий которой является оппозиция «вербализованность : : невербализованность» коммуникативного знака. Она выступает важной семиотической характеристикой акциональности опосредованной коммуникации, поскольку соотношение вербалики и невербалики обусловлено этнокультурными факторами.

Как тип коммуникативного действия, вербализованный в исходном тексте, влияет на его перевод?

Коммуникативное действие в качестве инициальной основы переводческого действия рассмотрим на материале текстов одного дискурса: актуального, глобально и лингвокультурно детерминированного, отражающего многообразие коммуникационных реалий туристического интернет-дискурса. Данный дискурс осуществляет взаимодействие в от- 
расли, которая, как показано в исследовании Э.Ю. Новиковой, влияет на укрепление межличностного и межкультурного взаимодействия и расширяет границы познания [Новикова, 2016а, с. 78].

\section{1. Целерациональное коммуника-} тивное действие «ожидаемо» в информационных жанрах любого медиадискурса, и их репрезентирующий характер (darstellend в типологии К. Райс) гипотетически должен быть выражен как в исходном, так и в целевом тексте.

Официальный туристический портал Берлина «VisitBerlin» является одним из крупнейших немецких многоязычных виртуальных проектов в сфере туризма и предлагает информацию для гостей столицы на 13 языках, включая китайский, арабский и японский. Иконическое оформление контента, посвященного достопримечательностям, почти полностью совпадает на всех языках. Безусловно, имеет место сокращение объема отдельных рубрик на всех языках, кроме исходного немецкого и глобального английского. Каковы особенности перевода данных информационно-энциклопедических текстов на русский язык?

Ведущую роль в этом направлении локализирующего перевода играет компрессия. Сокращаются как целые тексты, так и отдельные фрагменты, и не всегда элиминация оправдана, особенно при передаче прецедентной информации, значимой для знакомства с Берлином. Ср.:

Museumsinsel

Das Welterbe der Kultur in Berlin

Die Museumsinsel in Berlin ist ein grandioses Gesamtkunstwerk mit fünf weltweit renommierten Museumsbauten, die in einem außergewöhnlichen Ensemble versammelt sind. Zu den Highlights der Ausstellungen auf der Museumsinsel zählen u.a. die Nofretete und der Pergamonfries.

Музейный остров

Мировое культурное наследие

Берлинский Музейный остров - это северная оконечность острова Шпрееинзель, на которой расположен грандиозный архитектурный ансамбль, включающий пять музеев с мировым именем, собранных в необычайную композицию.

Museum Island

The world heritage of culture
Berlin's Museum Island is a magnificent work of art in its own right, an extraordinary ensemble of five world-renowned museums on an island in River Spree right in the heart of Berlin's city centre. The many highlights include the bust of Nefertiti and the Pergamon Altar.

(Visit Berlin. - Electronic data. - Mode of access: http://www.visitberlin.de. - Title from screen.)

Перевод на английский язык выполнен пословно, без сокращений, несмотря на общую тенденцию к значительному уменьшению объема текстов в глобальных версиях, которое, по мнению И.Д. Ромадиной, является одной из составляющих «процесса создания адаптированного для глобального получателя англоязычного вторичного текста» [Ромадина, 2016, с. 157].

В русскоязычном варианте имеет место компрессия в комплексе с семантическим перераспределением, реализованным с помощью лексических и грамматических трансформаций.

В тексте на немецком языке представлена важная для посетителя сайта информация о том, что в берлинских музеях можно увидеть такие шедевры мировой культуры, как Пергамский алтарь и бюст Нефертити. В тексте на русском языке этих сведений нет, информация дана только в частях гипертекста, посвященных отдельным музеям, однако вторичный текст на английском содержит указание на главные шедевры Музейного острова. Элиминация важной информации представляется не вполне логичной в тексте, peaлизующем целерациональное действие, ориентированном на максимально подробное представление данных - ведь создатели сайта, отправители данного текста, называют себя рекламными агентами Берлина (Wir sind die Berlin-Werber!).

Вероятно, на перевод влияет целерациональная установка на максимальную представленность информации о столице в глобализованной англоязычной версии сайта и сокращенную в локализованных версиях. Самый поверхностный анализ переводов текстов сайта на русский, турецкий, португальский, польский языки подтверждает высказанное предположение. Данные версии созданы позже английской, французской и испанской и в полной мере испытали на себе влияние акту- 
альной тенденции реализации оппозиции «глобализация : : локализация» в формировании межкультурного туристического дискурса [Romadina, Mityagina, 2017].

\section{2. Ценностно-ориентированное} коммуникативное действие доминирует в комбинациях с традиционным и аффективным в интерактивных персональных жанрах туристического интернет-дискурса - форумах, блогах, интернет-комментариях, ставших современными форматами дневников путешественников, путевых заметок и салонных разговоров о посещенных странах, увиденных достопримечательностях и т. П. Эти жанры транслируют сформировавшиеся ценности туристического дискурса в полном объеме. Объектами перевода данные жанры выступают исключительно редко, поэтому интереса с точки зрения оптимизации качества межкультурной коммуникации не представляют. Отметим, что ценностные акценты находят свое воплощение в переводах, актуальных вне влияния процессов глобализации.

Так, один из самых крупных и известных многопрофильных русскоязычных туроператоров Германии «Levitin Reisen» предлагает на сайте тексты и на русском, и на немецком языках, что представляется логичным и эффективным для максимального комфорта потенциальных клиентов: знание языков может быть разным, как и состав путешественников.

Компания учитывает ценностные установки и разный «горизонт ожидания» русскоязычных и немецкоязычных туристов.

Прагматику текста отражает уже название тура: Столица Российской империи / Sankt Petersburg entdecken, однако в русскоязычной версии акцент сделан на имперской истории Санкт-Петербурга, а в немецкоязычной версии подчеркивается «вводный» характер тура: город предстоит «открыть»entdecken.

В переводе описания тура в Санкт-Петербург имеет место прагматическая адаптация, например:

Обзорная экскурсия по городу «Портрет Великого города» познакомит вас с лучшими архитектурными ансамблями Северной столицы и самыми известными памятниками монументальной скульптуры, с удивительными панорамами невских берегов и полными очарования набережными малых рек. Вы увидите, что составило славу Петербурга, ставшего одним из шести самых красивых городов Европы.

Stadtrundfahrt mit den wichtigsten Sehenswürdigkeiten / Обзорная экскурсия с осмотром главных достопримечательностей (здесь и далее в примерах перевод на русский язык наш. - B. M.).

Экскурсия в Петропавловскую крепость знакомит с фортификационными сооружениями России XVIII века, с историей зарождения города в устье реки Невы, с крепостью-тюрьмой и одновременно с уникальным памятником архитектуры города - собором Святых апостолов Петра и Павла, позолоченный шпиль которого возвышается над городом.

Besichtigung des Territoriums der Peter-PaulFestung mit der Peter-Paul-Kathedrale, Begräbniskirche aller Zaren / Осмотр территории Петропавловской крепости с Петропавловским собором, усыпальницей всех царей.

(Levitin Reisen. - Электрон. дан. - Режим доступа: http://www.levitin.de/info/company/. - Загл. с экрана.)

В тексте на русском языке бренд-номинации Петербурга Великий город, Северная столица, один из шести самых красивых городов Eвропь отражают новые тенденции туристического дискурса, который в данном случае проявляет свой гибридный, синтетический характер и реализует черты рекламного дискурса. Это объясняется тем, что «Интернет выступает в качестве мультиплицирующего интерактивного пространства, которое успешно и эффективно умножает информационно-коммуникационный потенциал функционирующих текстов» [Митягина, Новикова, 2015 , с. 291]. В тексте на немецком языке данные дополнительные характеристики основной номинации бренда туристской дестинации не могут быть эксплицированы во всей полноте заданных прагматических и оценочных параметров, и ценностно-ориентированное коммуникативное действие, выраженное в исходном тексте, становится целерациональным в тексте перевода. Великим может быть, в принципе, город глобальной исторической и культурной значимости (в частности, Рим, Иерусалим, Париж и т. п.), а как Северная столица Санкт-Петербург известен только знающим историю России. Информация о 
Петропавловской крепости сокращается до минимума, но имеет место дополнение, которое повышает культурного-историческую значимость объекта и мотивирует на его посещение: Begräbniskirche aller Zaren / усыпальница всех ияарей. Эта денотативная составляющая вполне компенсирует не представленные в тексте сведения об истории зарождения города, уникальном соборе, позолоченный шпиль которого возвышается над городом. Заметим, что обозначение собора как усыпальницы всех изарей является фактической ошибкой, которой было легко избежать посредством употребления словосочетания всех российских императоров (aller russischen Kaiser).

Прагматическая адекватность переводческого решения такого плана становится условием верного «входа» в инокультурное пространство, поскольку «переводческая локализация предполагает передачу культурно-специфических особенностей, которые чаще всего эксплицируются в терминах, реалиях, топонимике, структуре и подаче текста, использовании языковых средств “вежливой” модальности, создании “живого” прагматически адекватного текста» [Новикова, 2016б, с. 179].

Рассмотрим вариант прагматического «оживления» значимой когнитивной информации - обращения к ценностям целевой аудитории с помощью приема конкретизации. Он позволяет эксплицировать важную для потенциальных туристов информацию, например, посетителям волгоградского музея «Старая Сарепта» сообщается:

Уникальный для России и Европы историкоархитектурный комплекс Сарепты создал особый микроклимат культурно-бытовой среды немецких переселенцев.

Das einmalige Museum „Alt-Sarepta“ bewahrt kostbare Objekte der deutschen HerrnhuterKolonisten aus dem 19. Jhdt. und gehört zum historisch-kulturellen Erbe Russlands und Europas.

(Многоязычный туристический интернетпортал города Волгограда и Волгоградской области «Волгоградский край - территория путешествий». - Электрон. дан. - Режим доступа: http:// volga-land.volsu.ru. - Загл. с экрана.)

Обратим особое внимание на возросшую в тексте перевода степень дифференциации: немецкие переселенцы конкретизированы до deutsche Herrnhuter-Kolonisten (немеикие колонисты-гернгутеры) (перевод наш. - В. М.), что важно для презентации музея потенциальному туристу из Германии. Таким образом, можно констатировать, что ценностная ориентированность коммуникативного действия задает в переводе необходимую степень детализации и форму акцентирования отдельных составляющих семантико-прагматического содержания номинаций туристического дискурса.

\section{3. Традиционные и аффективные} действия, как уже было отмечено, составляют основу функционирования персональных жанров туристического дискурса, однако реализация автостереотипов собственной лингвокультуры, инокультурных и межкультурных стереотипов, как и выражение эмоционального отношения к переживаемым впечатлениям имеют место в рекламных текстах дискурса:

Bier ist ein Naturprodukt

Seit über vierhundert Jahren braut Hofbräu München nach dem Deutschen Reinheitsgebot. Dieses einzigartige Verbraucherschutzgesetz aus dem Jahre 1516 ist das unverletzliche Gütesiegel für die Reinheit und Qualität unserer Biere.

Пиво - продукт натуральный

Уже более четырехсот лет Hofbräu München варит пиво, соблюдая закон Райнхайтсгебот. Этот уникальный нормативный акт, датированный 1516 годом и защищающий потребителей, является неприкосновенным знаком соответствия, гарантирующим чистоту и качество нашего пива.

(Staatliches Hofbräuhaus in München. - Electronic data. - Mode of access: https://www.hofbraeumuenchen.de/. - Title from screen.)

Приведенный пример является фрагментом гипертекста сайта знаменитого пивного ресторана Мюнхена «Hofbräuhaus München». Сайт представлен на немецком, английском и русском языках, что свидетельствует об особом отношении к русскоязычным посетителям и учете их иноязычных компетенций, с одной стороны, и стереотипном подходе к презентации Мюнхена, с другой стороны. В переводе на русский язык использованы подстановка и семантическое развертывание, оценочные лексические единицы и притяжательное местоимение (чистота и качество нашего пива) употреблены с целью соверше- 
ния получателем перевода целерациональных и ценностно-ориентированных действий.

Maibockanstich im Hofbräuhaus

Der Bock ruft

Es ist das älteste Bockbier Münchens. Und es wird jedes Jahr im Frühling frisch gebraut: Der Maibock im Hofbräuhaus.

Bernsteinfarben ist er, bemerkenswert sanft, süffig und stark, ein Höhepunkt des Bierjahres und ein gesellschaftliches Ereignis. Denn wenn der bayerische Finanzminister und der Direktor der Brauerei Hofbräu München alljährlich in der letzten Aprilwoche zum Maibockanstich einladen, dann kommt alles was in Politik, Wirtschaft und Kultur Rang und Namen hat ins Hofbräuhaus am Platzl. Sicherlich, es geht gesellig zu beim „O'zapft is”. Aber wer nur Gemütlichkeit erwartet, der sehe sich vor: Zum Maibockanstich wird „abgerechnet”, da wird „,derbleckt” und so manche „Watschn” an die „Großkopferten” verteilt.

Das war damals so wie heute. Schon der Dichter Ludwig Thoma hat in seinen legendären „Filserbriefen”, die in den Jahren zwischen 1909 und 1912 veröffentlicht wurden, die Szenerie unnachahmlich festgehalten: „Das Minisderium war fohlzelig versambeld und isd keine Entschuldigung wegen Influenza eingelaufen, wie es sonst der Fahl isd, und sogar die geschtierzten Minisder sind dagewesen und hawen sich an dem Freibier bedeiligd.“ ройхаус

Церемония откупоривания майбока в Хофб-

Бок зовет

Это старейший сорт бока в Мюнхене. И каждую весну его варят снова и снова: майбок в Хофбройхаус.

Янтарного цвета, замечательно мягкий, вкусный и крепкий, апогей пивоваренного года и общественное событие. Потому что, когда министр финансов Баварии и директор пивоварни Hofbräu München в последнюю неделю апреля рассылают приглашение на церемонию откупоривания майбока, в Хофбройхаус на Плацль стекаются все именитые деятели политики, экономики и культуры. Конечно, всеобщее дружеское единение при крике «Налито!» никто не отменял. Но если кто пришел в поисках уюта, берегись: на дегустации майбока вам могут «припомнить старое», «высмеять», а «зазнайку» - и «оплеухой» наградить.

Раньше все было точно так же. Еще писатель Людвиг Тома в своих легендарных «Письмах Фильзера», опубликованных в период с 1909 по 1912 год, бесподобно увековечил эту сцену: «Министерство собралось в полном составе, никто не сослался на грипп, как это часто бывает, и даже бывшие министры были там и налегали на бесплатное пиво».
(Staatliches Hofbräuhaus in München. - Electronic data. - Mode of access: https://www.hofbraeumuenchen.de/. - Title from screen.)

В приведенных примерах используются функционально адекватные, контекстуально актуальные соответствия, которые оптимальны для выражения традиционных коммуникативных действий: замечательно мягкий, никто не отменял, бесподобно увековечил, налегали. Данные переводческие решения основываются на учете коммуникативного потенциала этих фрагментов, на стремлении создать текст перевода как коммуникативный знак, отвечающий за выполнение комплексной социопрагматической программы.

\section{4}

Таким образом, можно констатировать, что социопрагматический подход к анализу процесса перевода эвристичен в осмыслении логики трансформаций, обусловленных задачами, которые решает текст, будучи комплексным коммуникативным знаком. Определение типа коммуникативного действия позволяет установить как инициальную основу совершаемого переводческого действия, так и сохранение / изменение типа коммуникативного действия в процессе и результате перевода. Преодоление сопротивления системы языка перевода является лишь «визуальной» составляющей совершаемых преобразований, и учет характеристик коммуникативных действий, детерминированных дискурсом, предоставляет новые аргументы в пользу подхода к пониманию перевода в качестве культурного трансфера: социокультурный семиозис возможен только через коммуникацию.

\section{ПРИМЕЧАНИЕ}

${ }^{1}$ Исследование выполнено при финансовой поддержке Российского фонда фундаментальных исследований (РФФИ) и Администрации Волгоградской области, проект № 17-14-34001 «Региональный туризм как фактор формирования дискурса и технологии перевода: номинативные и коммуникативно-прагматические конвенции текстов брендинга» (Региональный конкурс «Волжские земли в истории и культуре России» 2017 - Волгоградская область). 


\section{СПИСОК ЛИТЕРАТУРЫ}

Бархударов, Л. С. Язык и перевод (вопросы общей и частной теории перевода) / Л. С. Бархударов. - М. : Международные отношения, 1975. - 240 с.

Комиссаров, В. Н. Теория перевода (лингвистические аспекты) / В. Н. Комиссаров. - М. : Высшая школа, $1990 .-253$ с.

Латышев, Л. К. Курс перевода (эквивалентность и способы ее достижения) / Л. К. Латышев. М. : Международные отношения, 1981.-248 с.

Львовская, 3. Д. Современные проблемы перевода / З. Д. Львовская. - M. : URSS, 2014. - 224 с.

Миньяр-Белоручев, Р. К. Общая теория перевода и устный перевод / Р. К. Миньяр-Белоручев. М. : Воениздат, 1980. - 237 с.

Митягина, В. А. Социокультурные характеристики коммуникативного действия / В. А. Митягина. - Волгоград : Изд-во ВолГУ, 2007. - 356 с.

Митягина, В. А. Туристический дискурс: ценности, стереотипы, действия в контекстах социокультурной глобализации / В. А. Митягина, Э. Ю. Новикова // Лингвокультурные ценности в полиэтничном обществе / отв. ред. В. И. Карасик, Е. А. Журавлева. - Волгоград : Парадигма, 2015. С. 290-312.

Найда, Ю. К науке переводить / Ю. Найда // Вопросы теории перевода в зарубежной лингвистике : сб. ст. - М. : Международные отношения, 1978. - С. 114-137.

Новикова, Э. Ю. Лингвопрагматические характеристики интернет-дискурса медицинского туризма / Э. Ю. Новикова // Вестник Волгоградского государственного университета. Серия 2, Языкознание. -2016a. - Т. 15, № 3. - C. 78-86. -DOI: https:// doi.org/10.15688/jvolsu2.2016.3.8.

Новикова, Э. Ю. Перевод / локализация вебпортала: конвенциональные аспекты переводческой логистики / Э. Ю. Новикова // Лингвистическая и транслатологическая логистика многоязычного туристического интернет-ресурса / под общ. ред. В. А. Митягиной. - Волгоград : Изд-во ВолГУ, 2016б. -С. 173-181.

Рецкер, Я. И. О закономерных соответствиях при переводе на родной язык / Я. И. Рецкер // Вопросы теории и методики учебного перевода : сб. ст. - М. : Изд-во Акад. пед. наук РСФСР, 1950. С. $156-183$.

Ромадина, И. Д. Глобализация контента международного туристического сайта как задача перевода (на материале англоязычных сайтов) / И. Д. Ромадина // Филологические науки. Вопросы теории и практики. - 2016. - № 9 (63), ч. 1. - С. 154-159.

Федоров, А. В. Основы общей теории перевода / А. В. Федоров. - М. : Высшая школа, 1983. $303 \mathrm{c}$.
Catford, J. A linguistic theory of translation / J. Catford. - London : Oxford University Press, 1965. $-110 \mathrm{p}$.

Habermas, J. Sprechakttheoretische Erläuterungen zum Begriffder kommunikativen Rationalität/ J. Habermas // Intention - Bedeutung - Kommunikation / G. Preyer, M. Ulkan, A. Ulfig (Hrsg.). - Opladen : Westdeutscher Verlag, 1997.-S. 258-287.

Hönig, H. G. Strategie der Übersetzung. Ein Lehrund Arbeitsbuch Tübinger Beiträge zur Linguistik / H. G. Hönig, P. Kussmaul. - Tübingen : Gunter Narr, 1984. - $172 \mathrm{~S}$.

Lasswell, H. D. Power and personality / H. D. Lasswell. - N. Y. : Norton, 1948. - 262 p.

Prunč, E. Einführung in die Translationswissenschaft. Band 1. Orientierungsrahmen/E. Prunč.-Graz: Selbstverlag, Institut für Theoretische und Angewandte Translationswissenschaft, 2002. - 374 S.

Reiß, K. Adäquatheit und Äquivalenz als Schlüsselbegriffe der Übersetzungstheorie und -praxis / K. Reiß // Grundfragen der Übersetzungswissenschaft. Wiener Vorlesungen / M. Snell-Hornby, M. Kadric(Hrsg.). Wien : WUV-Universitätsverlag, 1995. - S 13-22.

Reiß, K. Grundlegung einer allgemeinen Translationstheorie / K. Reiß, H. J. Vermeer. Tübingen : Niemeyer, 1984. $-253 \mathrm{~S}$.

Reiß, K. Texttyp und Übersetzungsmethode / K. Reiß. - Heidelberg : Groos, 1983. - 146 S.

Risku, H. Translatorisches Handeln / H. Risku // Handbuch Translation / M. Snell-Hornby, H. G. Hönig, P. Kussmaul, P. A. Schmitt (Hrsg.). - Tübingen : Stauffenburg Verlag, Brigitte Narr GmbH, 2006. S. 107-112.

Romadina, I. Translation and localization of microtoponyms (based on Russian and English language texts of online tourism discourse) / I. Romadina, V. Mityagina// Xlinguae: European Scientific Language Journal. - 2017. - Vol. 10, iss. 2. - P. 112-124.

Shannon, C. E. A mathematical theory of communication / C. E. Shannon // Bell System Technical Journal. - 1948. - Vol. 27 (Part 1, July). - P. 379-423; Vol. 27 (Part 2, Oct.). - P. 623-656.

Vermeer, H. J. Skopos und Translationsauftrag / Hans J. Vermeer. - Heidelberg : Groos, 1989. - 164 S.

Weber, M. Wirtschaft und Gesellschaft. Grundriß der verstehenden Soziologie / M. Weber. - Tübingen : J. C. B. Mohr, 1976. - 346 S.

\section{REFERENCES}

Barkhudarov L.S. Yazyk i perevod (voprosy obshchey i chastnoy teorii perevoda) [Language and Translation (Questions of General and Special Translation Theory)]. Moscow, Mezhdunarodnye otnosheniya Publ., 1975. 240 p. 
Komissarov V.N. Teoriya perevoda (lingvisticheskie aspekty) [Theory of Translation (Linguistic Aspects)]. Moscow, Vysshaya shkola Publ., $1990.253 \mathrm{p}$.

Latyshev L.K. Kurs perevoda (ekvivalentnost $i$ sposoby ee dostizheniya) [The Course of Translation (Equivalence and Ways of Its Achieving)]. Moscow, Mezhdunarodnye otnosheniya Publ., $1981.248 \mathrm{p}$

Lvovskaya Z.D. Sovremennye problemy perevoda [Modern Problems of Translation]. Moscow, URSS Publ., 2014. 224 p.

Minyar-Beloruchev R.K. Obshchaya teoriya perevoda $i$ ustnyy perevod [General Theory of Translation and Interpreting]. Moscow, Voenizdat Publ., 1980. 237 p.

Mityagina V.A. Sotsiokulturnye kharakteristiki kommunikativnogo deystviya [Sociocultural Characteristics of Communicative Action: Monograph]. Volgograd, Izd-vo VolGU, 2007. 356 p.

Mityagina V.A., Novikova E.Yu. Turisticheskiy diskurs: tsennosti, stereotipy, deystviya v kontekstakh sotsiokulturnoy globalizatsii [Tourism Discourse: Values, Stereotypes, Actions in the Contexts of Sociocultural Globalization]. Karasik V.I., Zhuravleva E.A., eds. Lingvokulturnye tsennostiv polietnichnom obshchestve [Linguistic Cultural Values in a Multi-Ethnic Society]. Volgograd, Paradigma Publ., 2015, pp. 290-312.

Nida Ju. K nauke perevodit [Toward a Science of Translating]. Voprosy teorii perevoda $v$ zarubezhnoy lingvistike: sb. st. [Questions of Translation Theory in Foreign Linguistics: a Collection of Articles]. Moscow, Mezhdunarodnye otnosheniya Publ., 1978, pp. 114-137.

Novikova E.Yu. Lingvopragmaticheskie kharakteristiki internet-diskursa meditsinskogo turizma [Linguo-Pragmatic Features of the Medical Tourism Internet Discourse]. Vestnik Volgogradskogo gosudarstvennogo universiteta. Seriya 2, Yazykoznanie [Science Journal of Volgograd State University. Linguistics], 2016, vol. 15, no. 3, pp. 78-86. DOI: https://doi.org/10.15688/jvolsu2.2016.3.8.

Novikova E.Yu. Perevod / lokalizatsiya vebportala: konventsionalnye aspekty perevodcheskoy logistiki [Translation / Localization of the Web Portal: Conventional Aspects of Translation Logistics]. Mityagina V.A., ed. Lingvisticheskaya $i$ translatologicheskaya logistika mnogoyazychnogo turisticheskogo internet-resursa [Linguistic and Translational Logistics of a Multilingual Tourist Internet Resource]. Volgograd, Izd-vo VolGU, 2016, pp. 173-181.

Retsker Ya.I. O zakonomernykh sootvetstviyakh pri perevode na rodnoy yazyk [On the Regular Correspondences when Translating into One's Native Language]. Voprosy teorii i metodiki uchebnogo perevoda: $s b$. st. [Questions of Theory and Methodology of Educational Translation: a Collection of Articles]. Moscow, Izd-vo Akademii pedagogicheskih nauk RSFSR, 1950,pp. 156-183.

Romadina I.D. Globalizatsiya kontenta mezhdunarodnogo turisticheskogo sayta kak zadacha perevoda (na materiale angloyazychnykh saytov) [Globalization of Content of the International Tourism Website as a Target of Translation (by the Material of English-Language Websites)]. Filologicheskie nauki. Voprosy teorii i praktiki [Philological Sciences. Issues of Theory and Practice], 2016, no. 9 (63), part 1, pp. 154-159.

Fedorov A.V. Osnovy obshchey teorii perevoda [Fundamentals of General Theory of Translation]. Moscow, Vysshaya shkola Publ., 1983. 303 p.

Catford J. A linguistic theory of translation. London, Oxford University Press, 1965. 110 p.

Habermas J. Sprechakttheoretische Erläuterungen zum Begriff der kommunikativen Rationalität [Theoretical Explanations for the Concept of Communicative Rationality]. Hrsg. von G. Preyer, M. Ulkan, A. Ulfig. Opladen. Intention - Bedeutung Kommunikation [Intention - Meaning - Communication]. Westdeutscher Verlag, 1997, pp. 258-287.

Hönig H.G., Kussmaul P. Strategie der Übersetzung. Ein Lehr- und Arbeitsbuch TÜbinger Beiträge zur Linguistik [Strategy of Translation. A Teaching and Workbook. Tübingen Contribution to Linguistics]. Tübingen, Gunter Narr, 1984. 172 p.

Lasswell H.D. Power and personality. N.Y., Norton, 1948. 262 p.

Prunč E. Einführung in die Translationswissenschaft. Band 1. Orientierungsrahmen [Introduction to Translation Studies. Vol. 1. Orientation Frame]. Graz, Selbstverlag, Institut für Theoretische und Angewandte Translationswissenschaft, 2002. 374 p.

Reiß K. Adäquatheit und Äquivalenz als Schl Üsselbegriffe der Übersetzungstheorie und -praxis [Adequacy and Equivalence as Key Concepts of Translation Theory and Practice]. Grundfragen der Übersetzungswissenschaft. Wiener Vorlesungen [Basic Questions of Translation Studies. Viennese Lectures]. Wien, WUV-Universitätsverlag, 1995, pp. 13-22.

Reiß K., Vermeer H.J. Grundlegung einer allgemeinen Translationstheorie [Establishment of a General Translation Theory]. Tübingen, Niemeyer, 1984. $253 \mathrm{p}$.

Reiß K. Texttyp und Übersetzungsmethode [Text Type and Translation Method]. Heidelberg, Groos, 1983. 146 p.

Risku H. Translatorisches Handeln [Translator's Action]. Handbuch Translation [Manual Translation]. Hrsg. von Mary Snell- Hornby, Hans G. Hönig, Paul Kussmaul, Peter A. Schmitt. - unveränderter Nachdruck der 2. Auflage 1999. Tübingen, 


\section{ГЛАВНАЯ ТЕМА НОМЕРА}

Stauffenburg publishing house, Brigitte Narr GmbH, 2006. 434 p.

Romadina I., Mityagina V. Translation and localization of microtoponyms (based on Russian and English language texts of online tourism discourse. Xlinguae: European Scientific Language Journal, 2017, vol. 10, iss. 2, pp. 112-124.

Shannon C.E. A mathematical theory of communication. Bell System Technical Journal, 1948, vol. 27, pp. 379-423 (Part1, July), pp. 623-656 (Part 2, October).

Vermeer H.J. Skopos und Translationsauftrag [Skopos and Translation Orders]. Heidelberg, Groos, 1989. $164 \mathrm{p}$.

Weber M. Wirtschaft und Gesellschaft. Grundriß der verstehenden Soziologie [Economy and Society. Outline of Understanding Sociology]. Tübingen, J. C. B. Mohr publishing house, 1976. 346 p.

\section{Information about the Author}

Vera A. Mityagina, Doctor of Sciences (Philology), Professor, Head of the Department of Translation Theory and Practice, Volgograd State University, Prosp. Universitetsky, 100, 400062 Volgograd, Russian Federation, mityagina@volsu.ru, http://orcid.org/0000-0002-3997-3139

\section{Сведения об авторе}

Вера Александровна Митягина, доктор филологических наук, профессор, заведующая кафедрой теории и практики перевода, Волгоградский государственный университет, просп. Университетский, 100, 400062 г. Волгоград, Российская Федерация, mityagina@volsu.ru, http://orcid.org/ 0000-0002-3997-3139 